\title{
Green Synthesized BSA-Coated Selenium Nanoparticles Inhibit Bacterial Growth While Promoting Mammalian Cell Growth
}

This article was published in the following Dove Press journal: International Journal of Nanomedicine

\author{
Stanley Chung ${ }^{1 * *}$ \\ Renhui Zhou ${ }^{2, *}$ \\ Thomas J Webster (D) \\ 'Department of Chemical Engineering, \\ Northeastern University, Boston, MA \\ 021I5, USA; ${ }^{2}$ College of Chemistry, \\ Nankai University, Tianjin 30007I, \\ People's Republic of China \\ *These authors contributed equally to \\ this work
}

Background: Selenium is an essential trace element that is critical for many biological processes. Selenium nanoparticles (SeNPs) have shown more promise than other forms of selenium due to their low cytotoxicity and high bioavailability.

Methods: In this work, a one-step method was demonstrated for fabricating bovine serum albumin (BSA) stabilized SeNPs using ascorbic acid as the reductant. Human dermal fibroblasts were used to assess mammalian cytotoxicity, and Staphylococcus aureus and Escherichia coli were used to assess antibacterial performance.

Results: These SeNPs demonstrated increased fibroblast growth and reduced Staphylococcus aureus growth with a fibroblast $\mathrm{IC}_{50}$ value $(>681 \mu \mathrm{g} / \mathrm{mL}) 1$ order of magnitude higher than that for bacteria at day 1 .

Conclusion: This study demonstrated the promise of this synthesis process in achieving controllable selenium nanoparticle sizes without the use of strong basic solvents for improved antibacterial properties.

Keywords: selenium, green synthesis, nanoparticles, antibacterial, ascorbic acid

\section{Introduction}

Selenium (Se) is an essential trace element vital for many important processes for mammalian cells. Selenium intake leads to the formation of selenoproteins, which are crucial in modulating oxidative stress levels and play critical roles in reproduction, thyroid hormone metabolism, DNA synthesis, and protection from oxidative damage and infection. ${ }^{1}$ Through the modulation of pro-/anti-oxidant activity, Se also modulates the immune system response and tunes macrophage responses as the immune system is particularly sensitive to the balance of oxidants and antioxidants. ${ }^{2}$ Selenium deficiency $(<20 \mu \mathrm{g} / \text { day })^{3}$ may lead to Keshan's disease, ${ }^{4}$ a cardiomyopathy disorder, and KashinBeck's disease, ${ }^{5}$ a type of osteoarthritis. Recommended intake amounts for adults are between 55 and $400 \mu \mathrm{g} /$ day. $^{3}$

One promising area of research is the application of nanotechnology towards selenium fabrication and use. ${ }^{6-10}$ Nanoparticles (NPs) are particularly suitable as they possess high surface area to volume ratios, increased surface area, and increased interactions with biological targets, leading to higher availability and absorption by the host. ${ }^{11-13}$ In addition, selenium NPs (SeNPs) possess lower toxicity than their elemental form; in mice, the $\mathrm{LD}_{50}$ of selenomethionine was $25.6 \mathrm{mg} \mathrm{Se} / \mathrm{kg}$ compared with $92.1 \mathrm{mg} \mathrm{Se} / \mathrm{kg}$ for SeNPs. ${ }^{14}$ Researchers have shown that SeNPs may be used as
Correspondence: Thomas J Webster Department of Chemical Engineering, Northeastern University, 360 Huntington Avenue, 313 Snell Engineering Center, Boston, MA 02215, USA

Email th.webster@neu.edu 
a coating or directly in solution at dosages that reduce bacterial and cancerous growth while maintaining or promoting mammalian cell function. ${ }^{9,15-19}$

To fully utilize the potential of SeNPs, improved synthesis schemes are needed. Many SeNP schemes are multistep processes that involve the use of harsh solvents, such as benzene and toluene, ${ }^{20}$ and/or strong bases, such as sodium hydroxide. ${ }^{21} \mathrm{Li}$ and coworkers have found an alternative one-step method, using cysteine as a reductant. ${ }^{22}$ Instead of cysteine, Malhotra used ascorbic acid as a reductant for their system and dextran as a stabilizer. ${ }^{23}$ In this work, a synthesis scheme was developed using ascorbic acid and bovine serum albumin (BSA) as a stabilizer. Based on prior knowledge, SeNPs readily aggregate and are unstable without a stabilizer. BSA is a commonly used stabilizer that does not illicit toxic biological responses and is readily available. Here, these newly formed Se nanoparticles were then tested against mammalian and bacterial cell lines to assess their effect in modulating cellular activity.

\section{Materials and Methods}

\section{Selenium Nanoparticle Synthesis}

Bovine serum albumin (BSA, Sigma Aldrich, Saint Louis, MO)-coated selenium nanoparticles (SeNPs) were synthesized with sodium selenite, ascorbic acid and BSA in a one-step reaction. Specifically, $50 \mathrm{mM}$ ascorbic acid (Sigma Aldrich) was added dropwise to $1 \mathrm{~mL}$ of an aqueous solution containing $100 \mathrm{mM}$ sodium selenite and $10 \mathrm{mg} / \mathrm{mL}$ BSA. Upon addition of the reductant into sodium selenite, the solution turned into light yellow and eventually into dark red. The reaction proceeded for 30 mins before the nanoparticles were collected by centrifugation (11,000 rpm at $15 \mathrm{~min}$.) and were washed at least twice by dI $\mathrm{H}_{2} \mathrm{O}$ (dI $\mathrm{H}_{2} \mathrm{O}$, Milli-Q system, EMD Millipore, Billerica, MA). The molar ratio of ascorbic acid to sodium selenite and agitation speed were altered at 2 levels (1:5 and 1:6 for 100 and $600 \mathrm{rpm}$, respectively) to generate the 4 reaction conditions (Table 1 ) as these conditions were found to produce SeNPs with biologically relevant sizes.

Table I Experimental Conditions Chosen for Cell Studies

\begin{tabular}{|l|l|}
\hline $\begin{array}{l}\text { Molar Ratio (Sodium Selenite to } \\
\text { Ascorbic Acid) }\end{array}$ & $\begin{array}{l}\text { Agitation Speed } \\
\text { (rpm) }\end{array}$ \\
\hline I:5 & 100 \\
I:5 & 600 \\
I:6 & 100 \\
l:6 & 600 \\
\hline
\end{tabular}

\section{SeNP Characterization}

The SeNPs were characterized by dynamic light scattering (DLS, 90Plus Zeta, Brookhaven Instruments, Holtsville, $\mathrm{NY}$ ) with the manufacturer provided software to measure particle size. The NPs were first dried onto 300-mesh copper-coated carbon grids (Electron Microscopy Sciences, Hatfield, PA) before imaging by transmission electron microscopy (TEM, JEM-1010, Jeol, Peabody, MA). UVvisible spectra of the NPs were obtained from 200 to 1000 nm using a SpectraMax M3 (Molecular Devices, Sunnyvale, CA) to characterize the chemical properties of the SeNPs. The NPs were diluted $72 \mathrm{x}$ in $\mathrm{dI} \mathrm{H}_{2} \mathrm{O}$ before measurements. Previous studies have further characterized SeNPs commonly used in our experiments. ${ }^{15-17}$

\section{Mammalian Cell Activity Culture and Characterization}

Human dermal fibroblasts (HDF) were used as the model cell line for cytotoxicity studies. Human dermal fibroblasts (HDF, Lonza, Basel, Switzerland) at passage numbers 5-10 were cultured in Dulbecco's Modified Eagle Medium (DMEM, Sigma Aldrich) supplemented with $10 \%$ fetal bovine serum (FBS, Hyclone, Logan, UT) and $1 \%$ penicillin/streptomycin ( $\mathrm{P} / \mathrm{S}$, Sigma Aldrich) in a humidified incubator at $37^{\circ} \mathrm{C}$ and a $5 \% \mathrm{CO}_{2} / 95 \%$ air environment. HDFs were cultured to $\sim 90 \%$ confluence, rinsed with Dulbecco's phosphate-buffered saline (dPBS, Sigma Aldrich), and detached from the tissue culture surface with $0.25 \%$ trypsin-EDTA (Sigma-Aldrich).

HDF cells were then seeded into 96 well plates at 5000 cells/well, treated with $0.001-1 \mathrm{mg} / \mathrm{mL}$ selenium nanoparticles in 10x dilutions, and were grown for 1 day, 2 days and 4 days. Afterwards, cell activity was measured by the MTS (Cell Titer 96 Aqueous One Solution Cell Proliferation Assay, G3581 Promega) assay. The cell culture medium was aspirated before adding a 1:5 (media: MTS) solution for $2.5 \mathrm{~h}$ and before measuring the absorbance of each well by a SpectraMaxM3 plate-reader at $490 \mathrm{~nm}$. Controls included wells with no cells, and a standard curve was constructed with known cell numbers.

\section{Bacteria Experiments}

Escherichia coli (E. coli, ATCC no. 25922), multi-drug resistant (MDR) Escherichia coli (ATCC no. BAA-2471), and Staphylococcus aureus (S. aureus, ATCC no. 25923) were used as the model bacteria. For all bacteria tested, a single colony was picked from a stock agar plate and cultured overnight, $16-20 \mathrm{~h}$, in a $3 \%$ tryptic soy broth 
(TSB, Sigma Aldrich) at $37{ }^{\circ} \mathrm{C}$. Afterwards, the bacterial solution was diluted until the absorbance of the bacteria reached 0.52 at $562 \mathrm{~nm}$ for $S$. aureus and 1 at $600 \mathrm{~nm}$ for the $E$. coli species (both drug-resistant and non-drug resistant); these absorbances corresponded to a colony-forming unit count of $10^{9}$ based on previous experiments.

The bacteria were then diluted to $10^{6} \mathrm{CFU} / \mathrm{mL}$ for $S$. aureus and $10^{5}$ for the E. coli species and were seeded at $100 \mu \mathrm{L} /$ well in a 96-well plate. The bacteria were cultured with either no SeNPs (control) or 0.001-1-mg/ $\mathrm{mL}$ SeNPs in 10x dilutions overnight (16-20 h.). For the next day, the bacterial solutions were diluted $10^{5}$ fold and plated in $10-\mu \mathrm{L}$ spots on an agar plate to determine the number of CFUs. The agar plate was cultured for another $12-16 \mathrm{~h}$. before counting.

\section{Statistics}

All experiments were conducted in triplicate and repeated at least three times each. Analysis of variance (ANOVA) and Student's $t$-tests were used to determine the significance in the changes in cellular activity.

\section{Results}

\section{Selenium Nanoparticle Synthesis}

SeNPs were formed by adding the reductant, $50 \mathrm{mM}$ ascorbic acid, in specified molar ratios (Table 1) to an aqueous solution containing $100 \mathrm{mM}$ sodium selenite and $10 \mathrm{mg} / \mathrm{mL}$ of BSA and were measured by DLS as a preliminary screen (Table 2). At a 1:2 molar ratio addition of sodium selenite to ascorbic acid, the particles generated were in the $\mu \mathrm{m}$ range while at a 1:4 ratio and above, the particles generated were in the $\mathrm{nm}$ range. Agitation showed different effects on the size of the nanoparticles, depending on the molar ratio. At a 1:2 ratio, agitation did not appreciably affect the size of the particles generated. At a 1:4 ratio, increases in agitation directly increased the size of the nanoparticles produced.

Table 2 Dynamic Light Scattering (DLS) Measurements of Selenium Nanoparticles (SeNPs) at Different Reaction Conditions

\begin{tabular}{|l|l|l|l|l|}
\hline \multirow{2}{*}{} & & \multicolumn{3}{|l|}{ Agitation } \\
\cline { 3 - 5 } & & $100 \mathrm{rpm}$ & $\mathbf{4 0 0} \mathrm{rpm}$ & $\mathbf{6 0 0} \mathrm{rpm}$ \\
\hline Molar ratio & $1: 2$ & $753 \mathrm{~nm}$ & $803 \mathrm{~nm}$ & $721 \mathrm{~nm}$ \\
& $1: 4$ & $26 \mathrm{~nm}$ & $34 \mathrm{~nm}$ & $37 \mathrm{~nm}$ \\
& $1: 5$ & $23 \mathrm{~nm}$ & $15 \mathrm{~nm}$ & $42 \mathrm{~nm}$ \\
& $1: 6$ & $20 \mathrm{~nm}$ & $21 \mathrm{~nm}$ & $47 \mathrm{~nm}$ \\
\hline
\end{tabular}

Note: Shaded conditions were chosen to further cell studies
Interestingly, at ratios of $1: 5$ and $1: 6$, intermediate agitation $(400 \mathrm{rpm})$ reduced the nanoparticle size while high agitation $(600 \mathrm{rpm})$ increased the nanoparticle size. Above a ratio of 1:4, the sizing of the nanoparticles at the same agitation was similar (including at a ratio of 1:8, data not shown), possibly suggesting that the reaction had plateaued and no further increases in reductant concentration would further affect the reaction. Similarly, agitation above $600 \mathrm{rpm}$ (1100 and $1500 \mathrm{rpm}$, data not shown) did not appreciably change the nanoparticle size.

Following this initial screen, the shaded conditions (1:5 ratio at $100 \mathrm{rpm}, 1: 5$ ratio at $600 \mathrm{rpm}, 1: 6$ ratio at $100 \mathrm{rpm}$, and 1:6 ratio at $600 \mathrm{rpm}$ ) were chosen for further characterization and cellular testing due to their low polydispersity (Figure 1) and biological relevant sizing. Nanoparticles with dimensions between 10 and 100 $\mathrm{nm}$ in diameter are most effectively uptaken by the mammalian cells. ${ }^{13}$ The particles were imaged by TEM in order to confirm their sizing and geometry (Figure 2). As expected, the reaction generated the characteristic spherical nanoparticles, and ImageJ analysis of the TEM images showed that the nanoparticle distribution matched that from DLS (Figure 3).

UV-visible spectra captured the potential chemical changes due to the different reaction conditions (Figure 4). The absorbance of water was subtracted from that of the samples as water possesses strong signals in the $200-\mathrm{nm}$ region which may interfere with the signal from the SeNPs. All four conditions yielded similar trends in the UV-Vis spectra and a peak absorbance at $290 \mathrm{~nm}$.

\section{Impact on Mammalian and Bacterial Cells}

To assess the cytotoxicity of the SeNPs, human dermal fibroblasts (HDF) were chosen as the model system. An MTS assay was used to measure the cellular metabolic activity after exposure to SeNPs, and the signal of the treated cells was normalized to that of the no-treatment control (Figure 5). At the highest concentrations tested (1 and $0.1 \mathrm{mg} / \mathrm{mL}$ ), the SeNPs showed substantial cytotoxicity to the HDFs. However, at 0.01 and $0.001 \mathrm{mg} / \mathrm{mL}$, SeNPs increased the 1-day MTS signal of the HDF cells compared to the control $(\mathrm{p}<0.01)$. ANOVA analysis showed that the HDF response to the 4-reaction conditions was not statistically different except at the $0.001-\mathrm{mg} / \mathrm{mL}$ concentration at the 1-day time point, where both $600-\mathrm{rpm}$ reaction conditions showed improved MTS activity (21\% and 13\% increase for the 1:5 and 1:6 ratios, respectively). Both 1:5 ratio reaction conditions showed an increased 

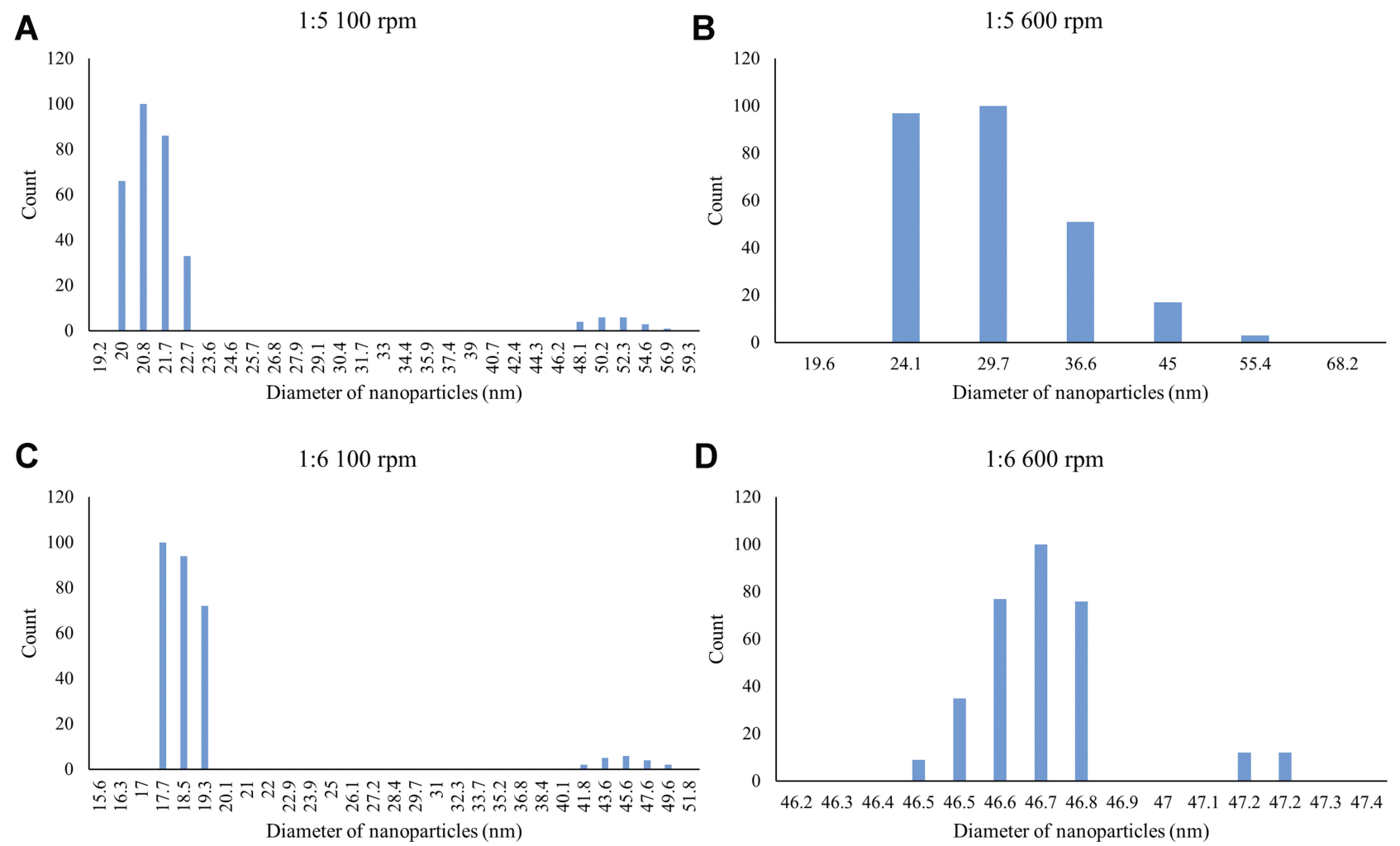

Figure I Histogram generated from dynamic light scattering (DLS) in number mode for the following conditions: (A) I:5 molar ratio of sodium selenite to ascorbic acid at 100 revolutions per minute $(\mathrm{rpm})$; (B) I:5 ratio at $600 \mathrm{rpm}$; (C) 1:6 ratio at $100 \mathrm{rpm}$; and (D) 1:6 ratio at $600 \mathrm{rpm}$.

MTS signal at $0.01 \mathrm{mg} / \mathrm{mL}(12 \%$ and $11 \%$ for 100 and $600 \mathrm{rpm}$, respectively). At 2 days, the difference was no longer statistically significant, and by 4 days, the SeNP treated cells showed reduced MTS activity $(\mathrm{p}<0.001)$.

Next, the ability of SeNP treatment for resisting bacterial growth was tested against both gram-positive (S. aureus) and gram-negative bacteria (E. coli and MDR E. coli, Figure 6). At the $1-\mathrm{mg} / \mathrm{mL}$ concentration, SeNP achieved a 10 -fold reduction in $S$. aureus growth at all conditions except at the $1: 5$ ratio and $100 \mathrm{rpm}$ in a statistically significant manner $(p<0.01)$. At the next highest dose, $S$. aureus reduction was still statistically significant at the $1: 6$ ratio condition $(\mathrm{p}<0.01)$, and the antibacterial performance was comparable to the $1-\mathrm{mg} / \mathrm{mL}$ dose $(45 \%$ reduction at $0.1 \mathrm{mg} / \mathrm{mL}$ compared to $62 \%$ at $1 \mathrm{mg} / \mathrm{mL}$ for the $1: 5$ ratio at $100 \mathrm{rpm}, 56 \%$ compared to $86 \%$ for the $1: 5$ ratio at $600 \mathrm{rpm}, 74 \%$ compared to $91 \%$ for the $1: 6$ ratio at $100 \mathrm{rpm}$, and $72 \%$ compared to $87 \%$ for the $1: 6$ ratio at $600 \mathrm{rpm})$. The lower dosages did not show a statistically significant reduction compared to the control. Treatment against the gram-negative bacteria showed no significant difference with the control.

\section{Discussion}

In this study, a novel synthesis scheme was proposed to fabricate SeNPs in a controllable and facile fashion that avoided the use of harsh solvents or bases. The parameters found to most influence nanoparticle size were agitation and molar ratio of reductant to reactant. The oxidation number is +4 for sodium selenite and 0 for elemental selenium. As such, four reduction reactions are required to transform the sodium selenite into SeNPs. Ascorbic acid has a reducing capacity of 1-2 so the 1:2 molar ratio is not enough to fully reduce selenite into elemental selenium, causing substantial aggregation. This is consistent with findings reported by $\mathrm{Li}$ and co-workers ${ }^{22}$ although the degree of aggregation is much more substantial in the current study.

At the 1:4 molar ratio, there is enough reductant to fully convert the selenite into SeNPs, yielding drastically different behavior. However, the molar ratio of the reductant is likely not in excess and would be more sensitive to changes in agitation. At the 1:5 and 1:6 ratios, the nanoparticle formation at the different agitations was very similar. It is likely that at these molar ratios, the reductant 

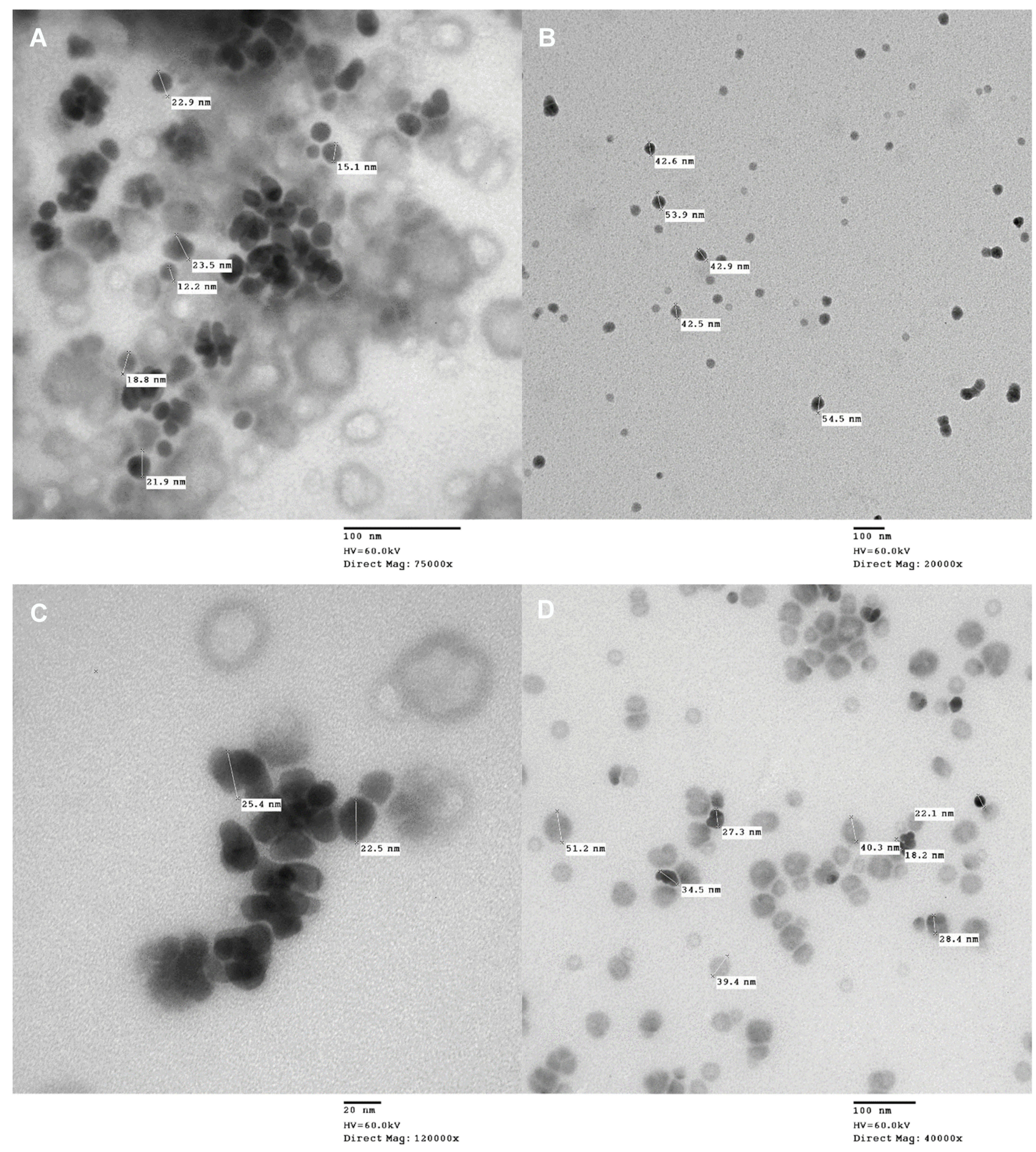

Figure 2 Transmission electron microscopy (T.E.M.) images of selenium nanoparticles (SeNPs) for the following conditions: (A) I:5 molar ratio sodium selenite to ascorbic acid at 100 revolutions per minute $(\mathrm{rpm})$; (B) I:5 ratio at $600 \mathrm{rpm}$; (C) I:6 ratio at $100 \mathrm{rpm}$; and (D) I:6 ratio at $600 \mathrm{rpm}$.

concentration reached an excess and further increases in reductant concentration would not affect the reaction.

The effect of agitation on the SeNP formation is similar to the mechanism first proposed by Li and Kaner. ${ }^{24}$ In their study, they found that mild/low agitation, 0-380 rpm, did not change the polyaniline particle diameter or distribution while high agitation, $1100 \mathrm{rpm}$, increased the size. Their proposed model suggested that nanoparticles formed initially by homogenous nucleation until the particles reached a critical size. At this point, Brownian motion and/or agitation will cause collisions between the different nanoparticle seeds, creating larger nanoparticles under 

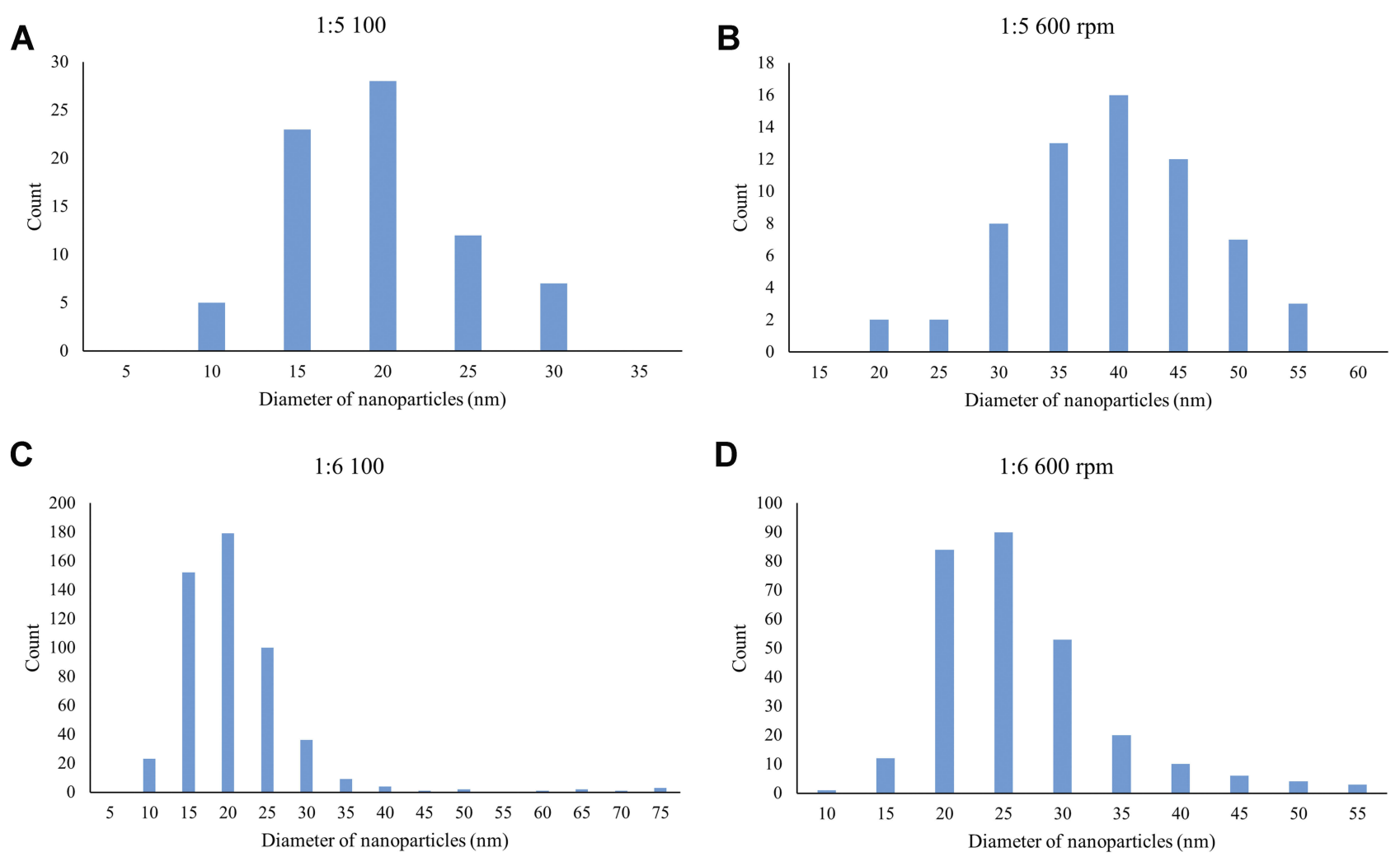

Figure 3 Histogram generated from transmission electron microscopy (T.E.M.) images for the following conditions: (A) I:5 molar ratio of sodium selenite to ascorbic acid at 100 revolutions per minute $(\mathrm{rpm}) ;(B)$ I:5 ratio at $600 \mathrm{rpm}$; (C) 1:6 ratio at $100 \mathrm{rpm}$; and (D) 1:6 ratio at $600 \mathrm{rpm}$.

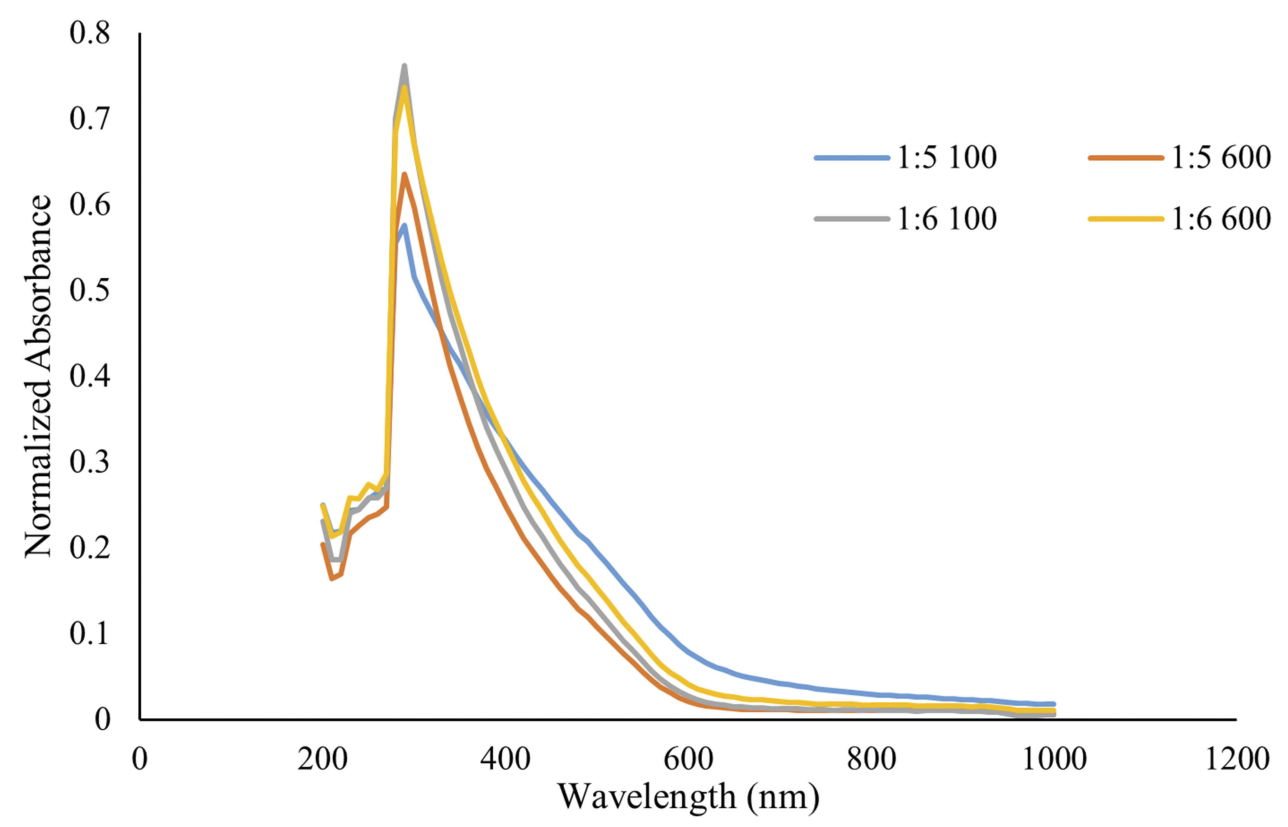

Figure 4 UV-Visible spectrum from 200 to $1000 \mathrm{~nm}$ for selenium nanoparticles (SeNPs) for the following conditions: 1:5 molar ratio of sodium selenite to ascorbic acid at 100 revolutions per minute $(\mathrm{rpm})$; I:5 ratio at $600 \mathrm{rpm}$; I:6 ratio at $100 \mathrm{rpm}$; and I:6 ratio at $600 \mathrm{rpm}$.

a heterogeneous nucleation mechanism. In the absence of agitation, this heterogeneous nucleation becomes limited and the nanoparticle size remains small. This model is also true for other inorganic nanoparticles, such as silica colloids. Sarin et $\mathrm{al}^{25}$ observed a similar phenomenon where the nucleation of SeNP in the presence of a carbon 


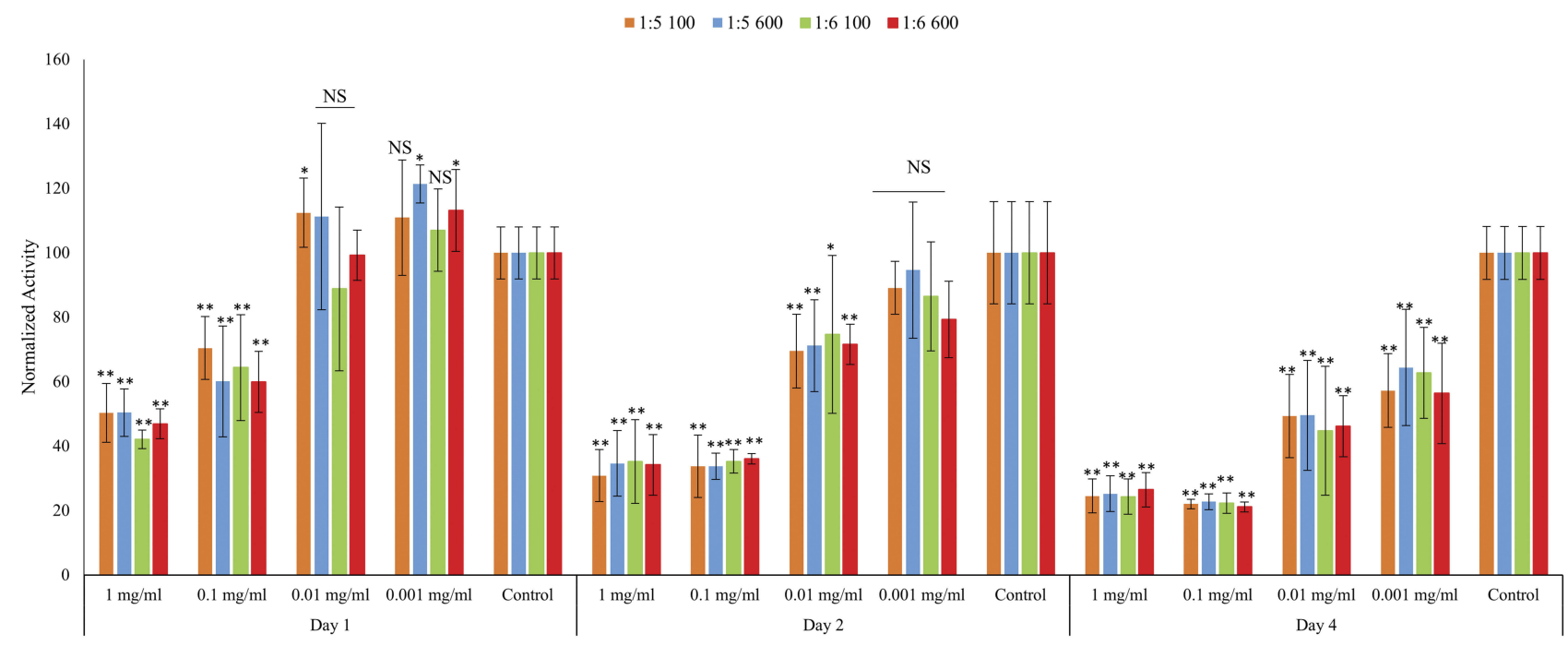

- $=\mathrm{p}<0.01$

$* *=\mathrm{p}<0.001$ compared to control on same day

Figure 5 MTS signal for human dermal fibroblast (HDF) for selenium nanoparticle (SeNP) treated cells compared to no treatment at I, 2, and 4 days. All tests were conducted in triplicate, $\mathrm{N}=3$. Data are average \pm standard deviation. ${ }^{*} p<0.0 \mathrm{I},{ }^{* *} p<0.00 \mathrm{I}$ compared to no-treatment control at the same day. NS $=$ not statistically significant.
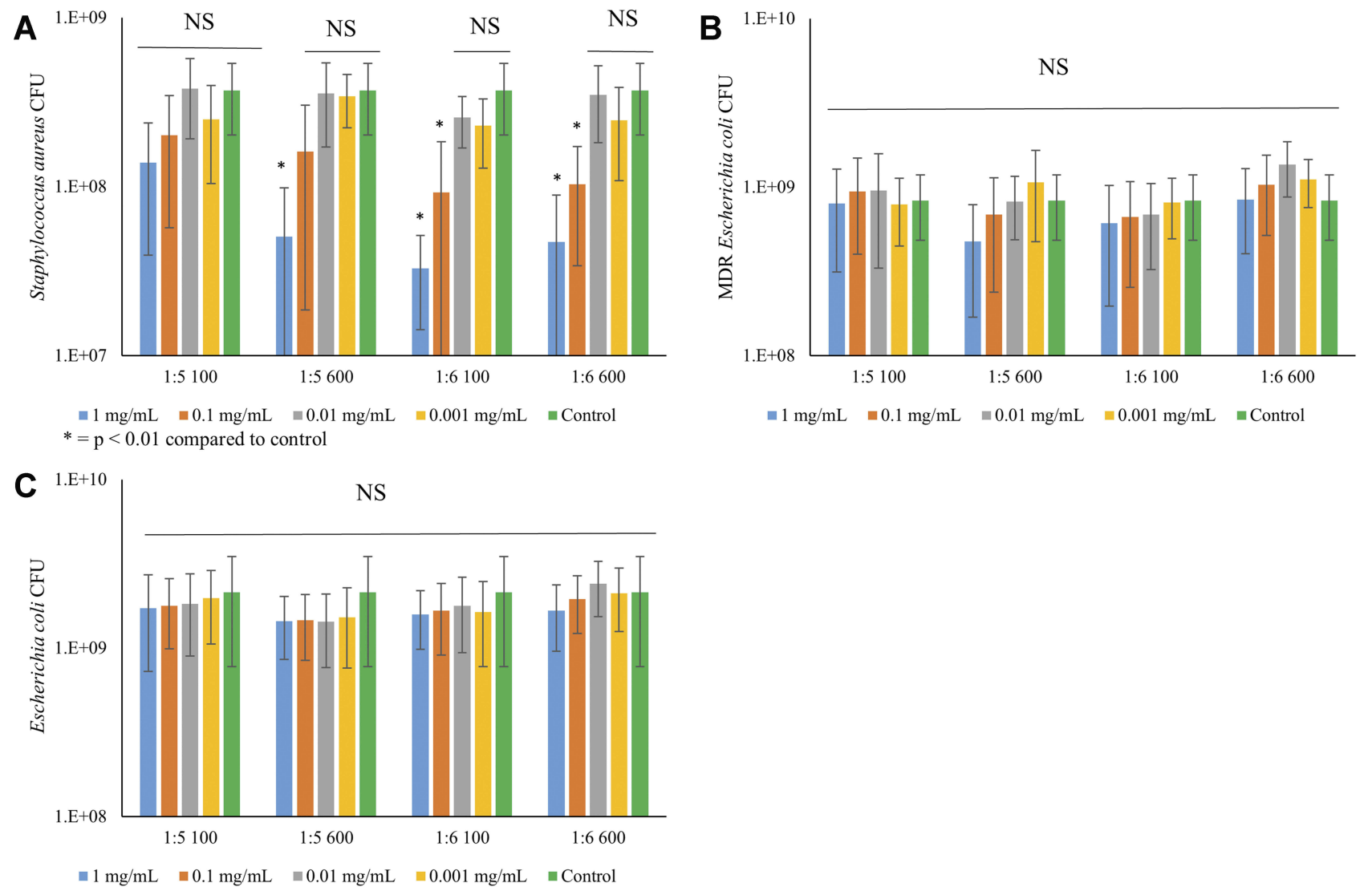

Figure 6 Colony-forming unit (CFU) of (A) Staphylococcus aureus, (B) multi-drug resistant (MDR) Escherichia coli, and (C) Escherichia coli after I-day treatment with selenium nanoparticles (SeNP). All tests were conducted in triplicate, $N=3$. Data are the average \pm standard deviation. ${ }^{*} p<0.01$ compared to no-treatment control. NS $=$ not statistically significant. 
substrate occurred as competition between homogeneous and heterogeneous nucleation, and other instances are highlighted here. ${ }^{26-28}$

The UV-visible spectra showed similar peaks for all four reaction conditions, suggesting that changes in the reaction conditions did not alter the chemical composition or shape of the nanoparticles. In Li's study, changes in the molar ratio of the reductant to selenite directly affected the morphology of the Se nanostructure, which directly altered the UV-visible spectra. $^{22}$ The UV-visible spectra (Figure 4) matched those reported by others for spherical SeNPs. ${ }^{22,29}$ TEM images (Figure 2) confirmed the formation of spherical SeNPs, and the distribution shown from the images matched those from the DLS measurements (Figures 1 and 3).

HDF were chosen as the model cell line as they have been widely used for testing cytotoxicity. ${ }^{7,30}$ The halfmaximal inhibitory concentration $\left(\mathrm{IC}_{50}\right)$ was determined for the reaction conditions at the different dosages of SeNP (Table 3). For the 1-day time point, HDF viability remained at or above $50 \%$ for all concentrations tested, ranging from $42 \%$ at the $1: 6$ ratio and $100 \mathrm{rpm}$ condition to $50 \%$ at the $1: 5$ ratio conditions. The 2-day and 4-day $\mathrm{IC}_{50}$ values remained similar for the different reaction conditions. The

$\mathrm{IC}_{50}$ values of these SeNPs were comparable to those fabricated from the more established method of using glutathione as a reductant and precipitating by bringing the $\mathrm{pH}$ into the alkaline region. Hassan reported an $\mathrm{IC}_{50}$ value of $59.61 \mu \mathrm{g} / \mathrm{mL}$ for HDFs grown after 3 days of incubation with SeNPs which was similar to the $\mathrm{IC}_{50}$ values reported here from the 2- and 4-day time points.

$S$. aureus and E. coli were chosen as the bacterial cell lines, because they are common bacterial contagions that are rapidly developing drug resistance. ${ }^{31}$ In addition, SeNP treatment towards these bacteria is well-characterized and serves as a good benchmark for evaluating the performance

Table $3 I_{50}$ Values of the Selenium Nanoparticles (SeNPs) on Human Dermal Fibroblasts (HDF) and Staphylococcus aureus (SA)

\begin{tabular}{|c|c|c|c|c|}
\hline & $\begin{array}{l}\text { Day I } \\
\text { HDF-IC }{ }_{50} \\
(\mu \mathrm{g} / \mathrm{mL})\end{array}$ & $\begin{array}{l}\text { Day } 2 \\
\text { HDF-IC } 50 \\
(\mu \mathrm{g} / \mathrm{mL})\end{array}$ & $\begin{array}{l}\text { Day } 4 \\
\text { HDF-IC }{ }_{50} \\
(\mu \mathrm{g} / \mathrm{mL})\end{array}$ & $\begin{array}{l}\text { Day I SA- } \\
\text { IC }_{50} \\
(\mu \mathrm{g} / \mathrm{mL})\end{array}$ \\
\hline $1: 5100$ & N/A & 59.24 & 9.30 & 334.27 \\
\hline I:5600 & $\mathrm{N} / \mathrm{A}$ & 61.02 & 9.75 & 88.99 \\
\hline $1: 6100$ & 681.85 & 66.42 & 7.41 & 49.24 \\
\hline I:6600 & 789.66 & 64.79 & 6.65 & 70.32 \\
\hline
\end{tabular}

for this synthesis scheme. Overall, the bacterial performance matched previously reported performance. ${ }^{17,29}$ Here, SeNPs achieved a 10 -fold reduction for S. aureus and $\mathrm{IC}_{50}$ values much lower than those for HDF treated at the same time $(334 \mu \mathrm{g} / \mathrm{mL}$ for the $1: 5$ ratio at $100 \mathrm{rpm}, 88.99$ for the $1: 5$ ratio at $600 \mathrm{rpm}, 49$ for the $1: 6$ ratio at $100 \mathrm{rpm}$, and 70 for the $1: 6$ ratio at $600 \mathrm{rpm}$ for $S$. aureus). In addition, the $\mathrm{IC}_{50}$ for $\mathrm{HDF}$ was an order of magnitude higher than the $\mathrm{IC}_{50}$ for $S$. aureus (Table 3) for all conditions tested except for the 1:5 ratio at 100-rpm reaction condition, giving a favorable safety window of at least 10:1 (at the 1:6 ratio at $600 \mathrm{rpm}, \mathrm{IC}_{50} \mathrm{HDF}=789$ $\mu \mathrm{g} / \mathrm{mL} / \mathrm{IC}_{50}$ S. aureus $=70 \mu \mathrm{g} / \mathrm{mL}$ ). Conversely, SeNPs were ineffective against both $E$. coli species. Reports in the literature have contrary effects of SeNP on E. coli; some researchers found antibacterial efficacy ${ }^{6,32,33}$ while others did not. ${ }^{29,34,35}$ At this moment, there is no conclusive mechanism for the bactericidal activity of SeNPs.

Generally, the modes of action for metallic particleinduced bacterial inhibition are through inactivation of vital proteins, generation of reactive oxygen species (ROS), membrane disruption, nutrient uptake interference, or genotoxicity. ${ }^{36}$ However, none of these proposed pathways fully accounted for reported anti-bacterial activity. Liu et al found that SeNP loaded into an anodized titanium nanotube repelled $E$. coli growth and identified three modes of action: membrane disruption, damage to adhesion-mediating proteins, and reactive oxygen species (ROS) generation. ${ }^{6}$ However, Zonaro found that the amount of ROS generated by SeNPs $(221.1-345.2 \mathrm{~nm})$ did not correlate with the bacterial inhibition. ${ }^{32}$ In addition, prior studies with SeNP-treated Staphylococcus epidermidis, a Gram-positive bacterium (submitted work) did not show damaged bacterial membranes, suggesting membrane disruption was not the primary mode of antibacterial activity and may account for why the SeNPs were ineffective against $E$. coli in this study. In general, some of the reported differences in bacterial response may be attributed to the different strains of bacteria used, and studies focusing on omics-based differences may better elucidate the mechanism of action and why there are contradictory reports in the literature.

In summary, a novel method for synthesizing BSAcoated SeNPs was reported here. The fabrication method was robust, facile, easily scalable, and controllable and avoided the use of harsh solvents or bases. Optimal agitation and reactant molar ratios were identified for generating SeNPs with biologically relevant dimensions. Similar to previous synthesis schemes, ${ }^{24,25}$ this method likely was 
initiated through homogeneous nucleation before proceeding into a heterogeneous nucleation phase. The nanoparticles here possessed comparable chemical properties as those from previous synthesis schemes towards HDF and bacterial cell culture. Future studies requiring the use of SeNPs may utilize this facile green reaction scheme for generating controllable and homogeneous effective SeNP populations.

\section{Acknowledgments}

The authors would like to thank the Department of Chemical Engineering at Northeastern University for funding, William Fowle for his help with the TEM, and the members of the Webster Nanomedicine Group for their invaluable assistance and help. R.H.Z.'s travel expenses were supported by Nankai University and lab expenses were supported by Northeastern University.

\section{Disclosure}

The authors report no conflicts of interest in this work.

\section{References}

1. Ross AC, Caballero B, Cousins RJ, Tucker KL, Ziegler TR. Modern Nutrition in Health and Disease. 11th ed. Mod Nutr Heal Dis Elev Ed; 2012.

2. Amir Aslani B, Ghobadi S. Studies on oxidants and antioxidants with a brief glance at their relevance to the immune system. Life Sci. 2016;146:163-173. doi:10.1016/j.lfs.2016.01.014

3. Institute of Medicine (US), Compounds I of M (US) P on DA and R. Dietary reference intakes for vitamin $\mathrm{C}$, vitamin $\mathrm{E}$, selenium, and carotenoids [Internet]. Diet Ref Intakes Vitam C, Vitam E, Selenium, Carotenoids. 2000. 1-529p. Available from: http://www.ncbi.nlm.nih. gov/pubmed/25077263\%0Ahttp://www.ncbi.nlm.nih.gov/books/ NBK225480/. Accessed December 31, 2019.

4. Chen X, Yang G, Chen J, Chen X, Wen Z, Ge K. Studies on the relations of selenium and Keshan disease. Biol Trace Elem Res. 1980;2:91-107. doi:10.1007/BF02798589

5. Jirong Y, Huiyun P, Zhongzhe Y, et al. Sodium selenite for treatment of Kashin-Beck disease in children: a systematic review of randomised controlled trials. Osteoarthr Cartilage. 2012:20(7):605-613.

6. Liu W, Golshan NH, Deng X, et al. Selenium nanoparticles incorporated into titania nanotubes inhibit bacterial growth and macrophage proliferation. Nanoscale. 2016;8:15783-15794. doi:10.1039/C6NR04 $461 \mathrm{~A}$

7. Yuan B, Webster TJ, Roy AK. Cytoprotective effects of cerium and selenium nanoparticles on heat-shocked human dermal fibroblasts: an in vitro evaluation. Int J Nanomed. 2016;11:1427.

8. Shirsat S, Kadam A, Mane RS, et al. Protective role of biogenic selenium nanoparticles in immunological and oxidative stress generated by enrofloxacin in broiler chicken. Dalt Trans. 2016;45:88 45-8853. doi:10.1039/C6DT00120C

9. Fernandes AP, Gandin V. Selenium compounds as therapeutic agents in cancer. Biochim Biophys Acta - Gen Subj. 2015;1850:1642-1660. doi:10.1016/j.bbagen.2014.10.008

10. Kalishwaralal K, Jeyabharathi S, Sundar K, Muthukumaran A. Sodium selenite/selenium nanoparticles (SeNPs) protect cardiomyoblasts and zebrafish embryos against ethanol induced oxidative stress. J Trace Elem Med Biol. 2015;32:135-144. doi:10.1016/j.jtemb.2015. 06.010
11. Chen G, Roy I, Yang C, Prasad PN. Nanochemistry and nanomedicine for nanoparticle-based diagnostics and therapy. Chem Rev. 2016;116:2826-2885. doi:10.1021/acs.chemrev.5b00148

12. Skalickova S, Milosavljevic V, Cihalova K, Horky P, Richtera L, Adam V. Selenium nanoparticles as a nutritional supplement. Nutrition. 2017;33:83-90. doi:10.1016/j.nut.2016.05.001

13. Goldberg M, Langer R, Jia X. Nanostructured materials for applications in drug delivery and tissue engineering. J Biomater Sci Polym Ed. 2007;18:241-268. doi:10.1163/156856207779996931

14. Wang $\mathrm{H}$, Zhang J, Yu H. Elemental selenium at nano size possesses lower toxicity without compromising the fundamental effect on selenoenzymes: comparison with selenomethionine in mice. Free Radic Biol Med. 2007;42:1524-1533. doi:10.1016/j.freeradbiomed.2007. 02.013

15. Wang Q, Webster TJ. Short communication: inhibiting biofilm formation on paper towels through the use of selenium nanoparticles coatings. Int J Nanomedicine. 2013;8:407. doi:10.2147/IJN. S37465

16. Tran PA, Webster TJ. Antimicrobial selenium nanoparticle coatings on polymeric medical devices. Nanotechnology. 2013;24:155101. doi:10.1088/0957-4484/24/15/155101

17. Tran PA, Webster TJ. Selenium nanoparticles inhibit Staphylococcus aureus growth. Int J Nanomed. 2011;6:1553. doi:10.2147/IJN.S25646

18. Bhattacharjee A, Basu A, Sen T, Biswas J, Bhattacharya S. Nano-Se as a novel candidate in the management of oxidative stress related disorders and cancer. Nucl. 2017;60:137-145. doi:10.1007/s13237016-0183-2

19. Pi J, Yang F, Jin H, et al. Selenium nanoparticles induced membrane bio-mechanical property changes in MCF-7 cells by disturbing membrane molecules and F-actin. Bioorg Med Chem Lett. 2013; 23:6296-6303. doi:10.1016/j.bmcl.2013.09.078

20. Mayers B, Jiang X, Sunderland D, Cattle B, Xia Y. Hollow nanostructures of platinum with controllable dimensions can be synthesized by templating against selenium nanowires and colloids. $J$ Am Chem Soc. 2003;125:13364-13365. doi:10.1021/ja0379722

21. Sarkar B, Bhattacharjee S, Daware A, Tribedi P, Krishnani KK, Minhas PS. Selenium nanoparticles for stress-resilient fish and livestock. Nanoscale Res Lett. 2015;10:371. doi:10.1186/s11671015-1073-2

22. Li Q, Chen T, Yang F, Liu J, Zheng W. Facile and controllable one-step fabrication of selenium nanoparticles assisted by 1-cysteine. Mater Lett. 2010;64:614-617. doi:10.1016/j.matlet.2009.12.019

23. Malhotra S, Jha N, Desai K. A superficial synthesis of selenium nanospheres using wet chemical approach. Int J Nanotechnol Appl. 2014;3:7-13.

24. Li D, Kaner RB. Shape and aggregation control of nanoparticles: not shaken, not stirred. J Am Chem Soc. 2006;128:968-975. doi:10.1021/ ja056609n

25. Sarin L, Sanchez VC, Yan A, Kane AB, Hurt RH. Selenium-carbon bifunctional nanoparticles for the treatment of malignant mesothelioma. Adv Mater. 2010;22:5207-5211. doi:10.1002/adma.201002607

26. Lee J, Yang J, Kwon SG, Hyeon T. Nonclassical nucleation and growth of inorganic nanoparticles. Nat Rev Mater. 2016;1:16034. doi:10.1038/natrevmats.2016.34

27. Kovalenko MV, Manna L, Cabot A, et al. Prospects of nanoscience with nanocrystals. ACS Nano. 2015;9:1012-1057. doi:10.1021/nn506223h

28. Thanh NTK, Maclean N, Mahiddine S. Mechanisms of nucleation and growth of nanoparticles in solution. Chem Rev. 2014;11 4:7610-7630. doi: $10.1021 / \mathrm{cr} 400544 \mathrm{~s}$

29. Singh N, Saha P, Rajkumar K, Abraham J. Biosynthesis of silver and selenium nanoparticles by Bacillus sp. JAPSK2 and evaluation of antimicrobial activity. Der Pharm Lett. 2014;6:175-181.

30. Geilich BM, Gelfat I, Sridhar S, van de Ven AL, Webster TJ. Superparamagnetic iron oxide-encapsulating polymersome nanocarriers for biofilm eradication. Biomaterials. 2017;119:78-85. doi:10. 1016/j.biomaterials.2016.12.011 
31. CDC. Antibiotic resistance threats in the United States, 2013. Current. 2013. Available from: http://www.cdc.gov/drugresistance/ threat-report-2013/index.html Accessed December 31, 2019.

32. Zonaro E, Lampis S, Turner RJ, Junaid S, Vallini G. Biogenic selenium and tellurium nanoparticles synthesized by environmental microbial isolates efficaciously inhibit bacterial planktonic cultures and biofilms. Front Microbiol. 2015;6:1-11. doi:10.3389/fmicb. 2015.00584

33. Wang Q, Larese-Casanova P, Webster TJ. Inhibition of various gram-positive and gram-negative bacteria growth on selenium nanoparticle coated paper towels. Int J Nanomedicine. 2015;10:2885.
34. Guisbiers G, Wang Q, Khachatryan E, et al. Anti-bacterial selenium nanoparticles produced by UV/VIS/NIR pulsed nanosecond laser ablation in liquids. Laser Phys Lett. 2015;12:16003. doi:10.1088/ 1612-2011/12/1/016003

35. Tran PA, O'Brien-Simpson N, Reynolds EC, Pantarat N, Biswas DP, O'Connor AJ. Low cytotoxic trace element selenium nanoparticles and their differential antimicrobial properties against $S$. aureus and E. coli. Nanotechnology. 2016;27:45101. doi:10.1088/0957-4484/27/4/045101

36. Lemire JA, Harrison JJ, Turner RJ. Antimicrobial activity of metals: mechanisms, molecular targets and applications. Nat Rev Microbiol. 2013;11:371-384. doi:10.1038/nrmicro3028

\section{Publish your work in this journal}

The International Journal of Nanomedicine is an international, peerreviewed journal focusing on the application of nanotechnology in diagnostics, therapeutics, and drug delivery systems throughout the biomedical field. This journal is indexed on PubMed Central, MedLine, CAS, SciSearch ${ }^{\mathbb{R}}$, Current Contents ${ }^{\mathbb{R}} /$ Clinical Medicine, $^{2}$
Journal Citation Reports/Science Edition, EMBase, Scopus and the Elsevier Bibliographic databases. The manuscript management system is completely online and includes a very quick and fair peer-review system, which is all easy to use. Visit http://www.dovepress.com/ testimonials.php to read real quotes from published authors. 